\title{
Article \\ Effects of Agility Training on Skill-Related Physical Capabilities in Young Volleyball Players
}

\author{
Chia-Hung Chuang ${ }^{1}$, Min-Hao Hung ${ }^{2}$, Chi-Yao Chang ${ }^{3}{ }^{\circledR}$, Yung-Yi Wang ${ }^{4}$ and Kuo-Chuan Lin ${ }^{3, *}$
}

1 Department of Recreation and Hospitality Management, Dahan Institute of Technology, Hualien County 97145, Taiwan; misvbeverydayc@hotmail.com

2 Office of Physical Education, National Chin-Yi University of Technology, Taichung City 411030, Taiwan; a2822180@gmail.com

3 Office of Physical Education, Chung Yuan Christian University, Taoyuan City 320314, Taiwan; anthonychang1124@gmail.com

4 Taoyuanshibadequda'an Elementary School, Taoyuan City 33465, Taiwan; wang95117@gmail.com

* Correspondence: misvb@cycu.edu.tw

Citation: Chuang, C.-H.; Hung, M.-H.; Chang, C.-Y.; Wang, Y.-Y.; Lin, K.-C. Effects of Agility Training on Skill-Related Physical Capabilities in Young Volleyball Players. Appl. Sci. 2022, 12, 1904. https://doi.org/ 10.3390/app12041904

Academic Editor: Alfonso Penichet-Tomás

Received: 15 December 2021

Accepted: 7 February 2022

Published: 11 February 2022

Publisher's Note: MDPI stays neutral with regard to jurisdictional claims in published maps and institutional affiliations.

Copyright: (C) 2022 by the authors. Licensee MDPI, Basel, Switzerland. This article is an open access article distributed under the terms and conditions of the Creative Commons Attribution (CC BY) license (https:// creativecommons.org/licenses/by/ $4.0 /)$.

\begin{abstract}
The aim of this study was to examine the effects of different agility training methods on skill-related physical capabilities in young volleyball players. Twenty-seven young female volleyball players were randomly assigned to a shuttle-run training group (STG, $n=9$ ), an agility-ladder training group (ATG, $n=9$ ), and a control group $(C G, n=9)$. The intervention program was carried out three times a week for six weeks. Before and after the training period, participants' $10 \mathrm{~m}$ sprint (10 MS), agility T-test, and digging agility test (DAT) performances were assessed. Withingroup analysis showed significant improvements $(p<0.05)$ in the DAT, agility T-test, and 10 MS performance from pre- to post-test for the STG $(6.08 \%, 2.64 \%$, and $5.68 \%$, respectively) and ATG $(4.05 \%, 3.28 \%$, and $3.27 \%$, respectively). In the group analysis, there were significant differences $(p<0.05)$ between the STG and CG in the DAT and agility T-test. The STG and ATG were significantly superior to the CG in the 10 MS $(p<0.05)$. In conclusion, the results indicate that appropriate agility training can enhance the agility of lateral movements and speed of sprinting, as well as enable players to rapidly complete movements during a moving defense.
\end{abstract}

Keywords: 10 m sprint; agility T-test; digging agility test; performance; defense

\section{Introduction}

With the advances in technology, sports are being scientifically tested and trained to enhance athletic performance, and any measurement is an assessment tool for physical exercise and science [1]. Having good explosive power and agility positively affect short sprinting or various physical activities, and the assessment of athletic performance usually includes the evaluation of straight sprinting, change-of-direction (agility), jumping, and aerobic metabolism [2,3]. For most athletes, agility is an important athletic ability and is often the key to victory or defeat [4]. In many sports settings, athletes must react to the ball's direction, the opponent's attacking movement, or the teammate's pass by moving quickly [5], for example, by stealing bases in baseball, passing in basketball, dodging in boxing, and six-point footwork in badminton. Agility is inextricably linked to muscle strength, reaction time, speed, explosive power, and coordination [6-8], and can even be said to be a combination of these basic athletic abilities. In competitive sports, agility is often used to define the defensive ability of athletes [9], and for volleyball players, agility training can improve their defensive ability and performance in volleyball $[5,10,11]$.

The defensive ability in volleyball (including serving-receiving and spiking) is the mainline of defense that prevents the opposing team from scoring on offense; if one cannot defend, one cannot disrupt the opponent's offense and one cannot build an organizational offense. According to Miskin et al. [12], the importance of ball handling, serving-receiving, 
and defense is higher for good women's volleyball teams, which is a difference between men's and women's volleyball because each round trip takes longer in women's volleyball. Previous studies indicate that elite teams are significantly better at serving and receiving than non-elite teams and that the quality of offense depends on the quality of handling, which, in turn, depends on the quality of serving-receiving or defense [13]. Thus, defense is a significant skill. Defensive techniques are highly associated with muscle strength, flexibility, coordination, and rapid reaction, and movement is effectively generated through the hip, knee, ankle, and foot muscles [14], which is related to the speed and space limitations of volleyball. In a fast and fluid game, the defender is often forced to make short and fast shifts; therefore, the faster the attack, the higher the efficiency $[15,16]$. With the offensive and defensive systems, teams at different levels present varying contents. This variation relies on the maturity and stability of the athletes, and continuous adjustments in the daily training process can improve the overall performance of the team.

Effective training methods help increase the player's reaction speed, which in turn shortens the overall reaction time and makes the shift speed of receiving the ball faster. However, the regular training routines are not sufficient stimulation for the improvement of agility and must be trained specifically. Yap and Brown [17] reported the specific adaptations needed to impose the demands' principle, 3-4 times a week, more on 1 day and less on the next. The main goal of training is to adapt the body to movement and improve agility through repetitive practice [18], which means the training variations will differ according to the length of the program, and the ability, skill, or personality of the individual. Commonly used training methods for agility include back-and-forth jumps, side jumps, multipurpose ladders for training, step hurdles, and wooden box training [19], which, for young volleyball players, are safe and effective training methods that can enhance agility, coordination, and quickness. For volleyball training, agility training is a good way for volleyball players to use their physical stamina and skills better to perform better. The subjects of this study were middle-school girls aged 12-15. Since young athletes are less stable mentally, they are more unstable in the execution of technical movements during intense matches, which affects the outcome of the game. Therefore, different types of training should be used to bring the body into good overall physical condition to increase young athletes' willingness to learn and engage in long-term training patterns. By providing six weeks of agility training to young female volleyball players in different ways, this study examines whether agility training has a positive effect on the physical characteristics and specific tests required for volleyball.

\section{Materials and Methods}

\subsection{Study Subjects}

This study was designed to evaluate the effects of a six-week agility training program for volleyball players; twenty-seven young female volleyball players were recruited. Participants were randomly divided into a shuttle-run training group $(\mathrm{STG}, \mathrm{n}=9$; age $=13.78 \pm 0.67$ years; height $=160.13 \pm 5.58 \mathrm{~cm}$; body mass $=51.89 \pm 7.56 \mathrm{~kg}$ ), an agility-ladder training group $($ ATG, $\mathrm{n}=9$; age $=14.20 \pm 1.14$ years; height $=163.94 \pm 7.34 \mathrm{~cm}$; body mass $=56.17 \pm 9.85 \mathrm{~kg})$, and a control group (CG, $\mathrm{n}=9$; age $=17.80 \pm 1.23$ years; height $=163.55 \pm 6.42 \mathrm{~cm}$; body mass $=56.96 \pm 8.21 \mathrm{~kg}$ ). Due to the small group of respondents, this study was treated as preliminary. The post-tests were conducted on 14 April 2014. The characteristics of the participants did not change between test sessions, and participants had to meet the following criteria to participate in the study: (i) no participation in any formal agility training program within three months before the study and (ii) participation in an agility training program for a minimum of three times a week for six weeks. All participants provided informed consent, and the Committee for the Protection of the Rights of Human Subjects granted approval for the project (Institutional Review Board of Fu Jen Catholic University, C102027). 


\subsection{Agility Training Procedure}

After a pre-test, participants in the ATG began the six-week agility training, following the protocol presented in Figure 1 and Table 1. For the STG, players were required to perform a shuttle-run for 8 sets for weeks 1 to 2, 10 sets for weeks 3 to 4 , and 12 sets for weeks 5 to 6 . For each shuttle-run, participants needed to complete 20 sidestep change-ofdirections and maintain a forward and low body position. Some studies recommended that the work-to-rest ratio was 1:3 for the participants in agility training $[20,21]$. Therefore, the time rest interval between sets was $60 \mathrm{~s}$. The CG performed regular team training routines. The duration of team volleyball training was $120 \mathrm{~min}$ and consisted of warm-up exercises (i.e., jogging, marching, back-kicking, front-kicking, foot touching, walking lunge, and hip hinge exercise) and technical and tactical tasks using different formats (i.e., serves, reception, sets, defense, spiking, blocking, and games). The STG and ATG performed three additional weekly training sessions. The ATG training program in this study was devised based on a previous study [22]. In addition, a certified strength and conditioning specialist supervised all training sessions to ensure that all warm-up activities and coordination exercises were completed using the correct technique.
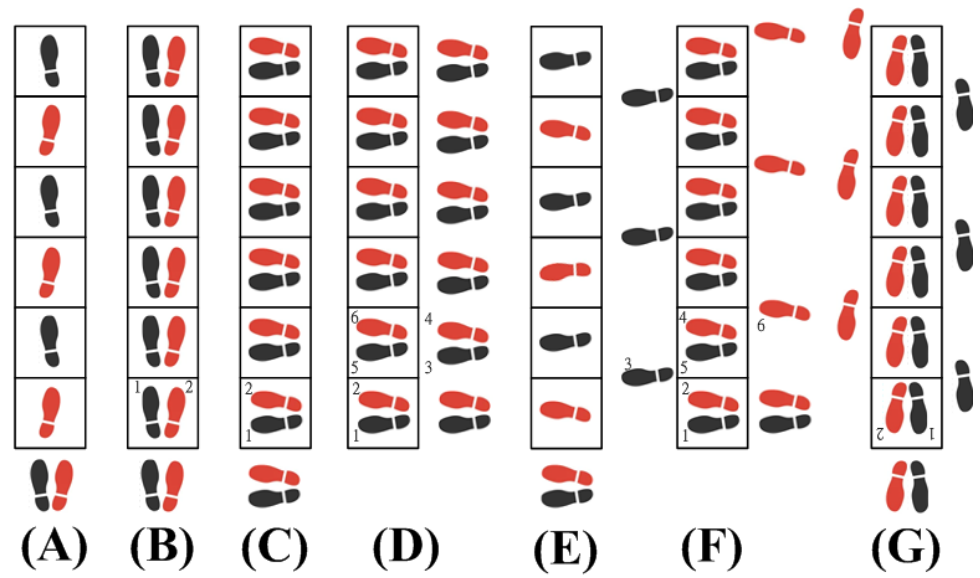

(C)

(D)

(E)

(F)

(G)
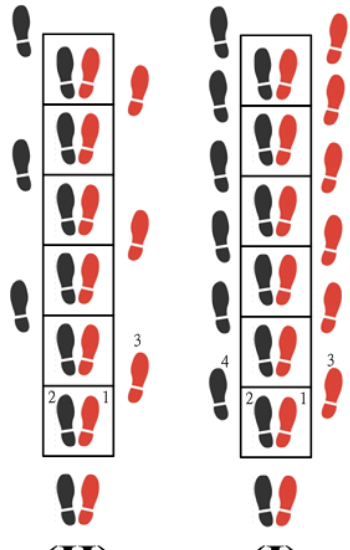

(H)

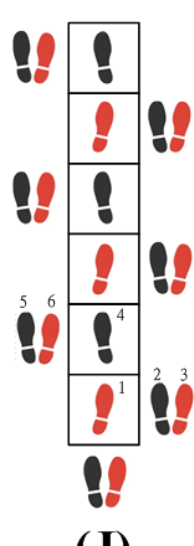

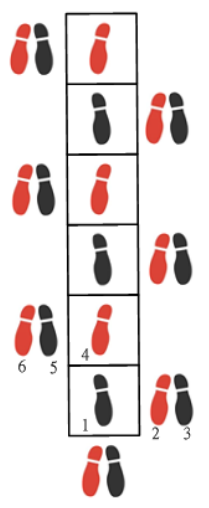

(K)

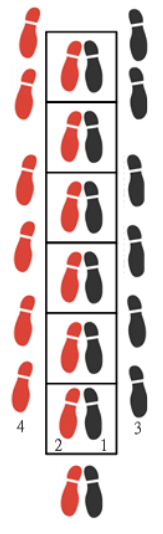

(L)

Figure 1. The schematic representation of the agility ladder exercises. (A) Frontal one in, one out, (B) Two in the hole, (C) Two in lateral, (D) Lateral two in, two out, (E) One lateral, (F) Lateral ickey shuffle, (G) Ickey shuffle backward, (H) Ickey shuffle, (I) Frontal two in, two out forward, (J) Zig-zag crossover shuffle, (K) Zig-zag crossover shuffle backward, (L) Frontal two in, two out backward. 
Table 1. The agility ladder exercises performed during the intervention program. Rest intervals between repetitions lasted $30 \mathrm{~s}$. Rest intervals between sets lasted $60 \mathrm{~s}$.

\begin{tabular}{llll}
\hline Agility Ladder Drills (Repetitions $\times$ Sets) & Weeks 1-2 & Weeks 3-4 & Weeks 5-6 \\
\hline Frontal one in, one out & $4 \times 1$ & & \\
Two in the hole & $4 \times 1$ & \\
Two in lateral & $4 \times 1$ & & \\
Lateral two in, two out & $4 \times 1$ & $2 \times 2$ & \\
One lateral & & $3 \times 2$ & \\
Lateral ickey shuffle & & $3 \times 2$ & $3 \times 2$ \\
Ickey shuffle backward & $3 \times 2$ & $3 \times 2$ \\
Ickey shuffle & & $3 \times 2$ \\
Frontal two in, two out forward & & $4 \times 2$ \\
Zig-zag crossover shuffle & & \\
Zig-zag crossover shuffle backward & & \\
Frontal two in, two out backward & & \\
\hline
\end{tabular}

\subsection{Testing Procedure}

Before the actual testing, participants jogged lightly for $5 \mathrm{~min}$ and then completed a general warm-up that included $5 \mathrm{~min}$ of static and dynamic stretching. The purpose of the warm-up was to increase the participants' heart rate, blood flow, core temperature, respiration, and range of motion. All participants were instructed and verbally encouraged to exert maximum effort in each test.

\subsubsection{Agility T-test}

Participants underwent a $36.56 \mathrm{~m}$ change-of-direction run in the agility T-test [23]. All participants were required to finish the agility $T$-test as quickly as possible, with fourdirection running including a $9.14 \mathrm{~m}$ sprint forward, $9.14 \mathrm{~m}$ right-hand sidestep, $9.14 \mathrm{~m}$ left-hand sidestep, and $9.14 \mathrm{~m}$ run backward (Figure 2). The dimensions of the fourdirectional change-of-direction speed (CODS) test were determined as timing gates. All participants were required to perform three trials, and their mean scores were recorded as the test results.

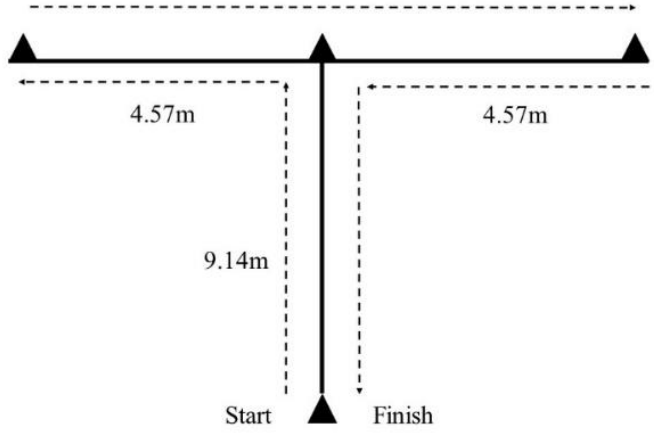

Figure 2. The illustration of the agility $T$-test. The agility $T$-test is a measure of four-directional change-of-direction speed.

\subsection{2. $10 \mathrm{~m}$ Sprint (10 MS)}

In this study, a self-made infrared photointerrupter timer was used for the $10 \mathrm{~m}$ sprint (10 MS) test. The time was recorded from the moment the infrared photointerrupter timer sensed participants passing the starting point until the moment it sensed participants passing the ending point. The time between the start- and end-point signals was retrieved as the measurement score. During the test, a standing start was utilized, followed by a full sprint upon hearing a whistle blow. Tests were conducted three times by each participant, and the average value of the three tests was calculated as the test results. 


\subsubsection{Digging Agility Test (DAT)}

In this study, the stand used to assess the participants' digging agility ability was made based on previous studies $[10,24]$. The testing system provided light stimuli to test the participants' digging ability (Figure 3). The ready position for defense in the test [24] was set at the sixth position on the volleyball court within a one square meter preparation area that was $1 \mathrm{~m}$ in front of the back line and involved waiting for light signals. Two sensors were placed $3 \mathrm{~m}$ in front of the back line, one volleyball height from the ground. The light signals were presented randomly at either side 10 times, for a total of 20 times with $8 \mathrm{~s}$ gaps [25]. When the lights were on, participants moved to touch the sensor in the same direction as they were defending. During the experiment, the system activated a light cue randomly. The evaluation computer system automatically recorded the reaction time during the test session.

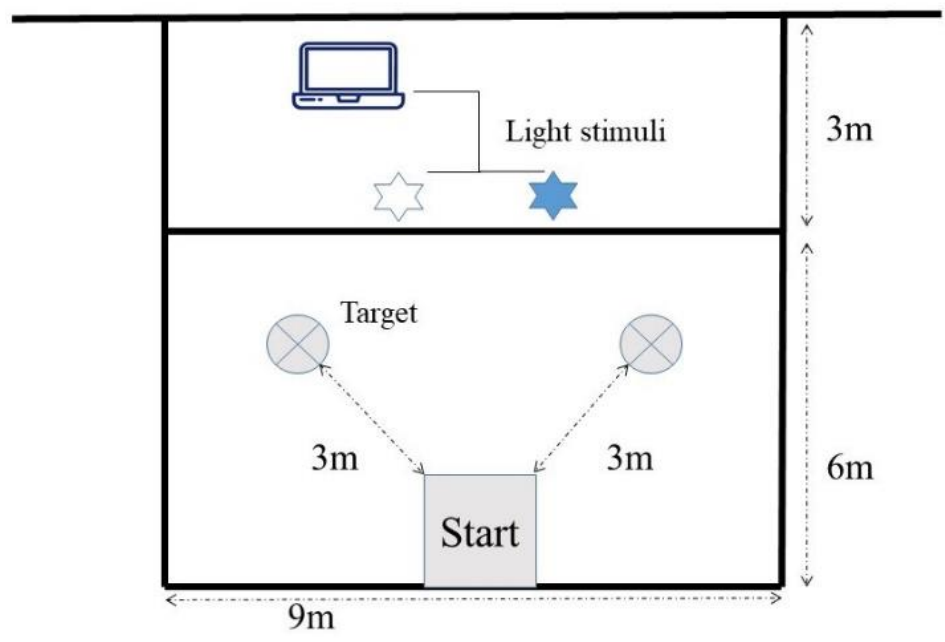

Figure 3. Diagram of the digging agility test for volleyball.

\subsection{Data Processing and Statistical Analyses}

All collected data were analyzed using a computer program written in MATLAB (Version R2008a; The MathWorks Inc., Natick, MA, USA) to calculate the participants' agility T-test, 10MS, and DAT scores. SPSS statistical software (version 20.0; SPSS Inc., Chicago, IL, USA) was used to assess the statistical significance of the data. Results are presented as mean \pm standard deviation, unless otherwise stated. The intra-class correlation (ICC) and coefficient of variation (CV) were applied to measure the variability. The Shapiro-Wilk test of normality was applied to check if the data were normally distributed. One-way analysis of covariance (ANCOVA) was conducted to examine the differences in variables between groups. The significance level was set at $\alpha=0.05$.

\section{Results}

The results of the Shapiro-Wilk test showed a normal distribution for all data. Results of the pre-test and post-test are presented in Table 2. The results indicated that the DATs of the STG, ATG, and CG were $1.48 \pm 0.08 \mathrm{~s}, 1.48 \pm 0.05 \mathrm{~s}$, and $1.48 \pm 0.06 \mathrm{~s}$ for the pre-test, and $1.39 \pm 0.09 \mathrm{~s}, 1.42 \pm 0.04 \mathrm{~s}$, and $1.47 \pm 0.06 \mathrm{~s}$ for the post-test, respectively. The analysis of covariance (ANOVA) revealed a significant difference between the three groups $\left(\mathrm{F}_{2,21}=5.512, p=0.012\right)$, and the STG performed significantly better than the CG $(p=0.011)$. The results for the agility T-test of the STG, ATG, and CG were $11.74 \pm 0.32 \mathrm{~s}, 12.21 \pm 0.34 \mathrm{~s}$, and $11.84 \pm 0.33 \mathrm{~s}$ for the pre-test, and $11.43 \pm 0.30 \mathrm{~s}, 11.81 \pm 0.37 \mathrm{~s}$, and $11.81 \pm 0.36 \mathrm{~s}$ for the post-test, respectively. The ANOVA demonstrated a significant difference between the three groups $\left(\mathrm{F}_{2,21}=4.336, p=0.021\right)$, and the result for the STG was significantly better than that for the CG $(p=0.026)$. The results of the $10 \mathrm{MS}$ for the STG, ATG, and CG were $2.11 \pm 0.12 \mathrm{~s}, 2.14 \pm 0.07 \mathrm{~s}$, and $2.14 \pm 0.16 \mathrm{~s}$ in the pre-test, and $1.99 \pm 0.12 \mathrm{~s}$, 
$2.07 \pm 0.06 \mathrm{~s}$, and $2.13 \pm 0.11 \mathrm{~s}$ in the post-test, respectively. The ANCOVA suggested a significant difference between the three groups $\left(\mathrm{F}_{2,21}=30.710, p=0.000\right)$, and both the STG and ATG performed significantly better than the CG $(p=0.017 ; p=0.045)$. In addition, a one-way ANOVA comparing the results of each group before and after training indicated that the STG and ATG showed significant improvements in the DAT, agility T-test, and 10 MS after six weeks of training, whereas the CG failed to achieve significant results in any of the three tests.

Table 2. The results of DAT, agility T-test, and 10 MS for pre-test and post-test.

\begin{tabular}{|c|c|c|c|c|c|c|c|}
\hline Item & Group & Pre-Test (CV) & ICC & Post-Test (CV) & ICC & $\mathbf{F}$ & $p$-Value \\
\hline \multirow{4}{*}{ DATs } & STG & $1.48 \pm 0.08(5.41 \%)$ & 0.95 & $1.39 \pm 0.09(6.48 \%)$ & 0.89 & \multirow{4}{*}{5.512} & \multirow{4}{*}{0.012} \\
\hline & ATG & $1.48 \pm 0.05(3.38 \%)$ & 0.95 & $1.42 \pm 0.04(2.82 \%)$ & 0.92 & & \\
\hline & CG & $1.48 \pm 0.06(4.05 \%)$ & 0.89 & $1.47 \pm 0.06(4.08 \%)$ & 0.90 & & \\
\hline & STG & $11.74 \pm 0.32(2.73 \%)$ & 0.81 & $11.43 \pm 0.30(2.62 \%)$ & 0.89 & & \\
\hline \multirow[t]{2}{*}{$T$-test } & ATG & $12.21 \pm 0.34(2.78 \%)$ & 0.91 & $11.81 \pm 0.37(3.13 \%)$ & 0.86 & \multirow[t]{2}{*}{4.336} & \multirow[t]{2}{*}{0.021} \\
\hline & CG & $11.84 \pm 0.33(2.79 \%)$ & 0.87 & $11.81 \pm 0.36(3.05 \%)$ & 0.82 & & \\
\hline \multirow{3}{*}{$10 \mathrm{MS}$} & STG & $2.11 \pm 0.12(5.69 \%)$ & 0.96 & $1.99 \pm 0.12(6.03 \%)$ & 0.97 & \multirow{3}{*}{30.710} & \multirow{3}{*}{0.000} \\
\hline & ATG & $2.14 \pm 0.07(3.27 \%)$ & 0.94 & $2.07 \pm 0.06(2.90 \%)$ & 0.90 & & \\
\hline & CG & $2.14 \pm 0.16(7.48 \%)$ & 0.90 & $2.13 \pm 0.11(5.16 \%)$ & 0.87 & & \\
\hline
\end{tabular}

\section{Discussion}

The findings revealed that the STG showed significant improvements in all three tests, which were $6.10 \%$ (DAT), $2.64 \%$ (agility T-test), and 5.68\% (10 MS), and performed significantly better than the CG. In terms of the ATG, the improvements were $4.05 \%$ (DAT), $3.28 \%$ (agility $T$-test), and 3.27\% (10 MS), but only the $10 \mathrm{MS}$ was significantly better than the other tests for the CG. For the CG, the improvements were $0.68 \%$ (DAT), $0.25 \%$ (agility $T$-test), and $0.47 \%$ (10 MS). The results show that the performance of the STG was the most effective. The main reason is that when the intervention was applied to the STG in the six-week $2 \mathrm{~m}$ shift training, the athletes used the hip-knee-ankle movement pattern to carry out left-right shifts. At the beginning of the movement, between the shift of the center of gravity of the feet, the muscles first contracted centrifugally and stored elastic potential energy, followed by rapid centripetal contraction, which triggered the stretch reflex and increased the speed of muscle contraction, allowing the stored elasticity to be released and increasing the performance of muscle strength [26]. The $2 \mathrm{~m}$ shuttle used in this study usually involves explosive training patterns, such as quick stops, fast starts, and changes in the direction of movement, in the same way as augmentation training, and can therefore be used to assist in the development of agility in young female athletes.

Several studies have indicated that agility training can provide performance advantages to the athletes in $10 \mathrm{~m}, 20 \mathrm{~m}$ sprint performance [22] and vertical jump simple reaction time tests [8]. Padrón-Cabo et al. [22] reported that the 6-week agility ladder training provides $2.54 \%$ enhancement on $10 \mathrm{~m}$ sprinting. Ho et al. [10] pointed out that the workload of a skill-based training program should be appropriate to improve the players' adaptability and achieve enhanced sports performance. In their researches [5,10], plyometric training was applied to the training program, which involves the features of agility. The studies showed that the college male volleyball players improved the results of the agility $T$-test by $2.01-2.68 \%$. These researches reported similar results to this study and provided positive evidence for the agility training effects.

Increasing muscle flexibility improves the stretch-shortening cycle and neural coordination during rapid contraction. This significantly enhances the player's agility to achieve the characteristics of the stretch reflex and muscle elasticity energy conversion, increase the unit of movement, establish a good response mechanism, increase the speed of the player's left-right shifts, heighten the defensive save rate, and enable the player to have an excellent defensive ability, respond randomly to various conditions on the court, and meet the demands of court movements by quickly changing attack and defense positions and 
changing movements. Many studies have shown that agility is not a single athletic ability, but it is influenced by both speed and explosive power $[27,28]$. Therefore, the maximum benefit of improving specific physical capabilities should be considered when scheduling training programs. Various training methods have been shown to have significant benefits in improving the basic or specific fitness of volleyball players. By using the principles of progression and overload, the muscles are loaded during exercise to enhance adaptability and improve athletic performance.

The results of the present study suggest that agility training significantly improves the performance of young female volleyball players in their sport-specific skills, and Potteiger et al. [29] attributed this improvement to improved motor unit recruitment through agility training, while the neural adaptation during exercise usually occurs in response to the coordination of movements after the presence of external stimuli [19]. In the present study, the results of the STG and ATG were not significant $(p>0.05)$ in any of the three tests. The main reason for this is that the movement patterns of the STG and ATG were consistent with the principles of agility training. so the differences in the improved movement patterns were not significant. The training program in this study used the agility ladder $2 \mathrm{~m}$ side shuttle for agility training and designed forward and left-right movements, with the movement pattern being similar to specific volleyball defensive saving techniques. This training pattern involves training the hamstring, hip, and medial femoral muscles [17], and helping athletes quickly shift the center of mass or center of gravity during movement transitions [30]. Improving the coordination of the lower limb muscles and controlling the shift of COG can effectively facilitate the rapid transition of leg lifts and the pace of volleyball players during mobile defense, thereby promoting the fluency and coordination of participants' movements. It is thus believed that exercise training programs should be designed based on the specific sport being played to obtain the maximum effects.

\section{Conclusions}

The results revealed that the agility ladder and $2 \mathrm{~m}$ side shuttle were effective in improving the volleyball expertise and agility of young female volleyball players. The agility ladder training provides the advantage for the field of change-of-direction test and the side shuttle-run training provides the advantage for sprinting and reactive-agility tests. When we train to promote agility in a particular sport, we should use the actual game setting, close to the sport, as the focus of training design to enhance agility and directly improve the player's skill in footwork technique, which is more helpful on the sport's field in the future.

Author Contributions: Conceptualization, C.-H.C. and Y.-Y.W.; methodology, K.-C.L.; software, K.-C.L.; validation, C.-H.C., Y.-Y.W. and K.-C.L.; formal analysis, M.-H.H.; investigation, M.-H.H.; resources, Y.-Y.W.; data curation, K.-C.L.; writing—original draft preparation, C.-H.C. and K.-C.L.; writing-review and editing, C.-Y.C. and K.-C.L.; visualization, M.-H.H.; supervision, C.-H.C.; project administration, K.-C.L.; funding acquisition, K.-C.L. All authors have read and agreed to the published version of the manuscript.

Funding: This research was funded by "Chung Yuan Christian University".

Institutional Review Board Statement: The study was conducted according to the guidelines of the Declaration of Helsinki, and approved by the Institutional Review Board (or Ethics Committee) of Fu Jen Catholic University (protocol code C102027 and date of approval 6 December 2013).

Informed Consent Statement: Informed consent was obtained from all subjects involved in the study.

Data Availability Statement: The data presented in this study are available on request from the corresponding author. The data are not publicly available due to privacy.

Conflicts of Interest: The authors declare no conflict of interest. 


\section{References}

1. Munro, A.G.; Herrington, L.C. Between-Session Reliability of Four Hop Tests and the Agility T-Test. J. Strength Cond. Res. 2011, 25, 1470-1477. [CrossRef] [PubMed]

2. Cronin, J.B.; Hansen, K.T. Strength and Power Predictors of Sports Speed. J. Strength Cond. Res. 2005, 19, 349-357. [CrossRef] [PubMed]

3. Young, W.B.; James, R.; Montgomery, I. Is muscle power related to running speed with changes of direction? J. Sports Med. Phys. Fit. 2002, 42, 282-288.

4. Young, W.; Farrow, D. A Review of Agility: Practical Applications for Strength and Conditioning. Strength Cond. J. 2006, 28, 24. [CrossRef]

5. Ho, C.-S.; Lin, K.-C.; Chen, K.-C.; Chiu, P.-K.; Chen, H.-J. System design and application for evaluation of blocking agility in volleyball. Proc. Inst. Mech. Eng. Part P J. Sports Eng. Technol. 2016, 230, 195-202. [CrossRef]

6. Marković, G.; Sekulic, D.; Marković, M. Is agility related to strength qualities?-Analysis in latent space. Coll. Antropol. 2007, 31, 787-793. [PubMed]

7. Paul, D.J.; Gabbett, T.J.; Nassis, G.P. Agility in team sports: Testing, training and factors affecting perfor-mance. Sports Med. 2016, 46, 421-442. [CrossRef] [PubMed]

8. Turna, B. The Effect of Agility Training on Reaction Time in Fencers. J. Educ. Learn. 2020, 9, p127. [CrossRef]

9. Farrow, D.; Young, W.; Bruce, L. The development of a test of reactive agility for netball: A new methodology. J. Sci. Med. Sport. 2005, 8, 52-60. [CrossRef]

10. Ho, C.-S.; Lin, K.-C.; Hung, M.-H.; Chang, C.-Y.; Chen, K.-C. System design and application for evaluation of digging agility in college male volleyball players. Proc. Inst. Mech. Eng. Part P J. Sports Eng. Technol. 2019, 233, 424-431. [CrossRef]

11. Wang, M.H.; Chen, K.C.; Hung, M.H.; Chang, C.Y.; Ho, C.S.; Chang, C.H.; Lin, K.C. Effects of plyometric training on surface electromyographic activity and performance during blocking jumps in college division I men's volleyball athletes. Appl. Sci. 2020, 10, 4535. [CrossRef]

12. Miskin, M.A.; Fellingham, G.W.; Florence, L.W. Skill importance in women's volleyball. J. Quant.-Tive Anal. Sports 2010, 6. [CrossRef]

13. Hughes, M.; Daniel, R. Playing patterns of elite and non-elite volleyball. Int. J. Perform. Anal. Sport 2003, 3, 50-56. [CrossRef]

14. Wu, C.C.; Wang, M.H.; Chang, C.Y.; Hung, M.H.; Wang, H.H.; Chen, K.C.; Ger, T.R.; Lin, K.C. The acute effects of whole body vibration stimulus warm-up on skill-related physical capabilities in volleyball players. Sci. Rep. 2021, 11, 1-7.

15. Castro, J.; Souza, A.; Mesquita, I. Attack Efficacy in Volleyball: Elite Male Teams. Percept. Mot. Ski. 2011, 113, 395-408. [CrossRef]

16. Palao, J.; Santos, J.; Ureña, A. Effect of the manner of spike execution on spike performance in volleyball. Int. J. Perform. Anal. Sport 2007, 7, 126-138. [CrossRef]

17. Yap, C.W.; Brown, L.E. Development of speed, agility, and quickness for the female soccer athlete. Strength Cond. J. 2000, $22,9$. [CrossRef]

18. Holmberg, P.M. Agility Training for Experienced Athletes: A Dynamical Systems Approach. Strength Cond. J. 2009, 31, 73-78 [CrossRef]

19. Craig, B.W. What is the scientific basis of speed and agility? Strength Cond. J. 2004, 26, 13-14. [CrossRef]

20. Barnes, M.; Attaway, J. Agility and Conditioning of the San Francisco 49ers. Strength Cond. J. 1996, 18, 10-16. [CrossRef]

21. Wilderman, D.R.; Ross, S.E.; Padua, D.A. Thigh Muscle Activity, Knee Motion, and Impact Force During Side-Step Pivoting in Agility-Trained Female Basketball Players. J. Athl. Train. 2009, 44, 14-25. [CrossRef]

22. Padrón-Cabo, A.; Rey, E.; Kalén, A.; Costa, P.B. Effects of Training with an Agility Ladder on Sprint, Agility, and Dribbling Performance in Youth Soccer Players. J. Hum. Kinet. 2020, 73, 219-228. [CrossRef] [PubMed]

23. Miller, M.G.; Herniman, J.J.; Ricard, M.D.; Cheatham, C.C.; Michael, T.J. The effects of a 6-week plyometric training program on agility. J. Sports Sci. Med. 2006, 5, 459-465. [PubMed]

24. Shondell, D.S.; Reynaud, C. (Eds.) The Volleyball Coaching Bible; Human Kinetics: Champaign, IL, USA, 2002.

25. Sheppard, J.M.; Gabbett, T.; Taylor, K.L.; Dorman, J.; Lebedew, A.J.; Borgeaud, R. Development of a repeat-ed-effort test for elite men's volleyball. Int. J. Sports Physiol. Perform. 2007, 2, 292-304. [CrossRef] [PubMed]

26. Baechle, T.R.; Earle, R.W. (Eds.) Essentials of Strength Training and Conditioning; Human Kinetics: Champaign, IL, USA, 2008.

27. Alemdaroğlu, U. The Relationship Between Muscle Strength, Anaerobic Performance, Agility, Sprint Ability and Vertical Jump Performance in Professional Basketball Players. J. Hum. Kinet. 2012, 31, 149-158. [CrossRef] [PubMed]

28. Sahin, H.M. Relationships between acceleration, agility, and jumping ability in female volleyball players. Eur. J. Exp. Biol. 2014, 4, 303-308.

29. Potteiger, J.A.; Lockwood, R.H.; Haub, M.D.; Dolezal, B.A.; Almuzaini, K.S.; Schroeder, J.M.; Zebas, C.J. Muscle power and fiber characteristics following 8 weeks of plyometric training. J. Strength Cond. Res. 1999, 13, 275-279.

30. Wheeler, K.W.; Sayers, M.G. Modification of agility running technique in reaction to a defender in rugby union. J. Sports Sci. Med. 2010, 9, 445. [PubMed] 